\title{
Teorias e plásticas do trágico da modernidade: Ernst Kirchner.
}

Eduardo Moura

\section{Resumo}

A representação pictórica da vida está historicamente entrelaçada à trajetória do pensamento ocidental. O presente trabalho trata de identificar traços das perplexidades da civilização moderna na arte expressionista. Pretende-se, através da análise de três obras pintadas por Ernst Kirchner, fazer considerações sobre trágico na cultura, tomando como eixo teórico Simmel e Freud. Os quadros correspondem a três momentos na obra do pintor: 1. O jovem Kirchner em Dresden e na Ilha de Fehmarn; 2. A fase na metrópole Berlim; e 3. O período do alistamento militar, que antecede à Primeira Guerra. Estabelecer um diálogo entre as questões apresentadas por esses autores e os quadros ajuda a apreender como as belas artes sintetizam em cores e traços a condição individual no ocidente moderno.

Palavras-chave: teoria social, artes plásticas, modernidade, expressionismo, Kirchner.

\begin{abstract}
The pictorial representation of life is historically interwoven into the trajectory of Western thought. The present work aims to identify traces of the perplexities of modern civilization in expressionist art. Through the analysis of three paintings by Ernst Kirchner, it intends to elaborate about the tragic in culture, taking as an axis the theoretical considerations of Simmel and Freud. These tables correspond to three moments in the painter's works: 1 . The young Kirchner in Dresden and in island of Fehmarn, 2. The phase in the Berlin metropolis, and 3. The period of military conscription, which predates World War I. Establishing a dialogue between the issues presented by these authors and the paintings may aid in the learning of how the Fine Arts synthesize in colors, strokes and brushes the individual condition in the modern West.
\end{abstract}

Keywords: social theory, fine arts, modernism, expressionism, Kirchner.

\section{Introdução}

A representação pictórica da vida está historicamente entrelaçada à trajetória do pensamento ocidental. A pintura é uma arte analógica marcada por uma distinção fundamental na passagem à modernidade. Pintar as coisas em si, tal como elas realmente são, e pintar as coisas tal como elas se apresentam aos sentidos - eis a cisão que remonta à fenomenologia de Kant, sobre a impossibilidade do conhecimento das coisas em sua essência. A experiência individual e subjetiva tende a ocupar os espaços das verdades que estão para além da compreensão, ao passo que a dimensão individual da vida foi um importante objeto de questionamento para as ciências humanas. Saber sobre o lugar do indivíduo, se ele está dentro 
ou fora da sociedade, se ele tende a realizar, no curso de sua conduta, movimentos de ruptura ou de integração em relação ao grupo e os efeitos dessa tensão - eis o problema recorrente nos textos sobre a cultura ocidental moderna. Doar-se ao mundo, renunciar às vontades e ímpetos em nome da segurança e da preservação do ambiente civilizado que, não obstante, destrói as possibilidades de desenvolvimento do espírito em sua totalidade. Por volta dos anos 1890, com a popularidade dos textos de Nietzsche, dois pensadores críticos da modernidade assumem papel marcante ao edificar epistemes dentro das esferas específicas da psicanálise e da sociologia. Freud e Simmel, enquanto autores que se debruçam sobre o tema da crise do indivíduo moderno, formam a base teórica a partir da qual se pretende levantar a questão do drama da civilização, mesmo drama que ganhou contornos e cores nos quadros do pintor expressionista Ernst Kirchner. O presente artigo trata de identificar a partir do quadro Marcella (1910) um diagnóstico crítico da modernidade capaz de dialogar com as teorias desses autores.

\section{O Expressionismo de Kirchner}

$\mathrm{Na}$ arte moderna, diante dos estilos que em maior ou menor grau abandonaram o desejo de reprodução rigorosa e exata daquilo que se entende como realidade, as obras de cada artista se diferenciam entre si pela criação de valores bastante particulares. O trágico nas obras dos pintores de vanguarda do início do século $\mathrm{XX}$ se manifesta através da interiorização, manifestação de uma dimensão abissal da vida, elaborada internamente pelo indivíduo a partir da interação com o mundo. A expressão de singularidades na pintura encontra espaço favorável a partir dos pintores que tentaram de alguma forma superar a mera impressão ótica em relação às luzes. Nessa linha, a passagem do pós-impressionismo ao expressionismo representa o movimento que culmina na preocupação essencial com a carga emocional do artista, em contraste com o Impressionismo francês.

De acordo com Sabine Fehlemann (2000), a arte expressionista provoca uma distorção e articulação das figuras em provimento de uma energia vital capaz de gerar uma tensão psicológica e, assim, uma caracterização subjetiva do objeto retratado. $\mathrm{O}$ formato realista fica subordinado ao emocional, condição que solta o movimento dos pincéis. O comprometimento dos traços e da distribuição de cores é tão somente com a tentativa de traduzir sentimentos. Mais que qualquer explicação técnica, o apelido de "câmara de horrores" dado às primeiras 
exposições expressionistas retrata o impacto que gerou essa arte na sociedade europeia da passagem ao século XX. Dessa forma, o trágico foi o tema que permeou os quadros. As inclinações naturalistas, ou seja, a aceitação dos prazeres, instintos e sensações vívidas como prescrição da conduta moral atribuía um tom convergente com a filosofia germânica. Sob um contexto rico em contradições, visto o projeto de modernidade que apresentava uma série de problemas ao indivíduo, o movimento que abre as vanguardas do século XX nasce entoado pela ideia de crise. $\mathrm{O}$ expressionismo nasce desse ambiente complexo, como produto do cruzamento de uma série de fatores políticos, culturais e filosóficos.

O expressionismo pressupõe uma atitude volitiva, ao contrário do impressionismo, que assume posição sensitiva no processo criativo. Há uma corrente e historiadores que consideram o expressionismo como anti-realista; no entanto não é essa a leitura que Giulio Carlo Argan faz. Segundo o autor (1997: 228), o expressionismo é realista assim como o impressionismo; não elabora realidades próprias, para além da experiência humana. Acontece que, ao contrário da transcendente tendência simbolista, o expressionismo se desenha como uma arte engajada. O comprometimento político está não somente na tentativa de incidir sobre realidades históricas, mas também por partir da experiência individual para colocar o problema da relação concreta com a sociedade. A arte expressionista é, portanto, realista e essencialmente política. De acordo com Argan, o expressionismo nasce no seio da modernidade e não em oposição a ela; nasce a partir da experiência de se estar imerso nesse mundo intenso e automatizado, complexo e estimulante, que ora acolhe, ora rejeita. A orientação nietzschena, nesse caso, é patente: a consciência é a vida e a vida é a vontade de lutar contra as estruturas e sistemas lógicos, contra a rigidez das regras que enquadram os homens (WOLF, 2004: 13-14). A cidade, nesse sentido, é zona favorável à formação dessa dinâmica asfixiante. Era preciso respirar ou responder, exteriorizar essas experiências. Nos artistas, tais experiências foram expressas sob o tom sombrio e angustiado. Ernst Kirchner revela em seu diário a sensação que atravessava seus quadros.

Mi obra procede de la nostalgia de la soledad. Siempre he estado sólo, cuanto más estaba con gente, más sentía mi soledad, me sentía rechazado, aunque nadie me rechazaba. Eso causa una profunda tristeza, que cedía ante el trabajo (KIRCHNER, E, In: WOLF, 2004:77).

Kirchner buscava expressar seus sentimentos em relação à vida. Para tanto, adotou um estilo antiacadêmico visando transmitir suas sensações de pessimismo em relação ao mundo. 
Quando deixou Dresden rumo a Berlim, o forte impacto na vida metropolitana passou a ser tema de seus quadros. Kirchner admite que foi vítima de uma excitação psíquica vivendo em Berlim. Como resultado, desenhos apressados e nervosos permitem que o observador participe da atmosfera da época- "espelham o ritmo das sensações de um ser humano da nossa época" (2000:110).

\begin{abstract}
Kirchner reacciona de forma ambivalente ante el tópico sobre el antagonismo entre "cultura" y "civilización". Según determinados tradicionalistas, la civilización era el resultado del dinero y la industria, a los quales se oponía la cultura, que abarcaba todo lo bello y estético. La civilización, por tanto, sería el resultado de la urbanización, palpable en los horribles rasgos de la vida moderna. El arte debía pasar por alto la civilización y, a cambio, dirigir su atención a la armonía de unos tiempos pasados más felices (WOLF, 2004: 14).
\end{abstract}

Segundo Norbert Wolf (2004), a atmosfera da metrópole alemã, ao mesmo tempo em que problematizava a vida, exigia uma arte que não fosse subordinada à técnica. Os artistas acompanhavam melancólicos as transformações e diante disso, somente a ligação com a natureza seria capaz de fazer emergir uma arte autêntica. Daí o tom nostálgico.

Os expressionistas possuem uma preocupação especial com a técnica, com o ato de pintar. Segundo Argan (1997: 238), os expressionistas defendem que na verdadeira arte criativa, a imagem, seja ela mental ou ótica, não deve preexistir à ação; a imagem não deve ser algo posto ou pré-concebido; deve se fazer ou se tornar imagem. O devir da imagem está em conformidade com os movimentos populistas, o que revela a posição ideológica do estilo. Argan explica que para os expressionistas, a técnica é trabalho antes de ser estilo. Assim, essa arte se aproxima da cultura operária ao passo que renuncia a qualquer vínculo com a cultura dirigente. A arte é práxis, uma atitude moral, segundo os próprios integrantes. Enquanto trabalho, a técnica privilegia a arte das gravuras sobre madeira, ou xilogravura. Argan explica que uma imagem expressionista não pode ser entendida sem considerar a arcaica, artesanal e popular arte de talhar em madeira. Arraigada na tradição cultural alemã, a xilogravura exige a força das mãos a pressionar a madeira com um objeto de metal. Tal força é reproduzida na imagem pictórica, como se tentasse reproduzir a violência exercida sobre a matéria. A distribuição de cores rompe com a verossimilhança e depende apenas da intenção do pintor de atribuir significado, o que implica na formação de um juízo. Dessa forma, o quadro suscita um posicionamento moral ou afetivo, que se manifesta através da idéia de deformação (1997:240). 


\begin{abstract}
A poética expressionista, que, no entanto, permanece sempre, fundamentalmente, idealista, é a primeira poética do feio: o feio, porém não é senão o belo decaído e degradado. Conserva seu caráter ideal, assim como os anjos rebeldes conservam, mas sob o signo negativo do demoníaco, seu caráter sobrenatural - a condição humana, que para os expressionistas alemães é precisamente um anjo decaído. Há, portanto, um duplo movimento: a queda e degradação do princípio espiritual ou divino que, fenomenizando-se, une-se ao princípio material; ascensão e sublimação do princípio material para unir-se ao espiritual. Esse conflito ativo determina o dinamismo, a essência dionisíaca, orgiástica e ao mesmo tempo trágica, da imagem e seu duplo significado de sagrado e demoníaco (ARGAN, 1997: 240).
\end{abstract}

Representar o espiritual, expressar sensações... As inclinações do expressionismo são marcas das preocupações e ideias de um determinado momento histórico. Na passagem ao Século XX, a riqueza de contradições nas relações, o espaço caótico e a velocidade dos movimentos são traços de um tempo que inspirou tendências artísticas. Os expressionistas, com suas deformações da realidade, mostravam com maior veemência possível um pessimismo em relação ao mundo. Trata-se de uma pintura que foge das regras tradicionais do equilíbrio e da harmonia para dar a dimensão da tragédia que a vida moderna se tornou. $\mathrm{O}$ expressionismo reforça o olhar da amargura presente nas relações entre os homens e na natureza. Por essa razão, é tão importante, pois está intimamente associado, e mesmo posicionado, como o primeiro grande movimento preocupado em representar sentimentos humanos.

\title{
O Mal-estar em Freud
}

Segundo Freud, a produção de algo para o mundo, de expressar algo que encontre um correlativo para lidar com nossos estados de sensação remonta à tensão entre os princípios do prazer e da realidade. O hiato entre desejo e satisfação impõe ao ser humano a condição que deve ser estabelecida entre prazer e realidade: no desenvolvimento da criança, o alargamento da capacidade de esperar corresponde ao gradual predomínio do princípio da realidade, fundamental para produzir um sujeito civilizado. Assim, o sentimento do ego surge dessa separação entre a realidade e o prazer. Forma-se, assim, uma estrutura tríade que pode ser pensada como a instância do prazer, a instância da realidade e o ego, que se constitui pela experiência do indivíduo no mundo. Freud buscava entender a lógica dos conteúdos inconscientes da mente que se manifestam através de palavras, atos e imaginações, utilizandose dos métodos de associação livre e transferência. Inspirado em uma concepção do aparelho 
psíquico de morfologia "arqueológica" (ou seja, em "camadas superpostas"), entende que, na mente, o passado se modifica e pode assumir novas formas ou disfarces, mas nunca se erradica totalmente. Por esse caminho, cabe fazer "escavações na mente".

Apesar de ser um impulso do ego a busca pela satisfação, tendência característica do princípio do prazer, podemos verificar em nossas próprias experiências que não há uma dominância dos prazeres no curso dos processos mentais, pois a busca do prazer desmedido pode se revelar um caminho arriscado no que se refere à autopreservação.

\begin{abstract}
Sob a influência dos instintos de autopreservação do ego, o princípio de prazer é substituído pelo princípio de realidade. Esse último princípio não abandona a intenção de fundamentalmente obter prazer; não obstante, exige e efetua o adiamento da satisfação, o abandono de uma série de possibilidades de obtê-la, e a tolerância temporária do desprazer como uma etapa no longo e indireto caminho para o prazer. Contudo, o princípio do prazer persiste por longo tempo como o método de funcionamento empregado pelos instintos sexuais, que são difíceis de 'educar', e, partindo desses instintos, ou do próprio ego, com freqüência consegue vencer o princípio de realidade, em detrimento do organismo como um todo (FREUD, 1996a:6).
\end{abstract}

O inconsciente, embora controle nossas vidas em nome do prazer, é tornado aceitável para a consciência através do princípio da realidade. Freud se inclinava na tentativa de entender como os instintos sexuais se acomodam nas convenções sociais e no código moral. Para as pretensões do presente trabalho, atemo-nos a pensar na psicanálise à luz do drama da civilização que está expresso na pintura moderna. Nesse sentido a necessidade de expressão das sensações é o ponto que permeia os quadros expressionistas e serve como ponto de partida para expor o choque entre o princípio do prazer e o princípio da realidade. Ao por em questão o papel da razão como guia do pensamento e da ação, Nietzsche, assim como Freud, chama atenção para a dimensão ilógica da vida, habitada pelas paixões e ímpetos. E o que os artistas desse tempo buscavam era a manifestação de algo interior, a "necessidade interna" de expressar uma vontade de não se sabe o quê.

O prazer pleno, que se perdeu na ruptura da unidade corporal com a mãe, se torna o objetivo a ser resgatado pelo ser humano, que acredita ser evitável esse sofrimento causado pela realidade. Da plenitude do prazer ao enfrentamento da realidade, onde o indivíduo precisa abdicar do desejo para se juntar, se associar e viver em civilização. De acordo com Freud, a condição de existência da civilização consiste em abrir mão do desejo em nome da 
concessão ao Outro, ou seja, do predomínio do princípio da realidade sobre o princípio do prazer $^{1}$.

O sentimento de culpa, impulsionado pelo medo da perda do amor do outro, pelo medo do desamparo, é intensificado no sentido de levar sempre o outro em consideração, seja no ato de agir ou no ato de pensar. Desenvolvemos a consciência, uma instância mental que mantém vigilância e exerce a censura sobre ações e intenções do ego. Assim, "a felicidade constitui um problema da economia da libido" (1997: 33). Moderação dos investimentos libidinosos é a marca do indivíduo civilizado.

Existe, portanto, uma instância do aparelho psíquico onde estão as normas. O sofrimento causado pelo relacionamento com outros homens está calcado na capacidade de se ver no outro, uma parcela do outro prevista em nós. Uma sequência lógica refaz o percurso que culmina na crise do indivíduo moderno. Imaginemos um homem sozinho, que precisa se associar em nome de sua preservação e do aumento de seus poderes, mas que para se associar deve abrir mão de alguns de seus desejos. Uma vez em conformidade com a sociedade, estará amparado e seguro; receberá, por assim dizer, o amor do próximo. No entanto, a ruptura com o código instituído implica em sanções e na possibilidade da perda do amor - não mais estará amparado pelos outros. Essa é a condição da civilização (Freud, 1997:25).

\begin{abstract}
A liberdade do indivíduo não constitui um dom da civilização. Ela foi maior antes da existência de qualquer civilização, muito embora, é verdade, naquele momento então não possuísse, na maior parte, valor, já que dificilmente o indivíduo se achava em posição de defendê-la. O desenvolvimento da civilização impõe restrições a ela, e a justiça exige que ninguém fuja a essas restrições. O que se faz sentir numa comunidade humana como desejo de liberdade pode ser sua revolta contra alguma injustiça existente, e desse modo esse desejo pode mostrar-se favorável a um maior desenvolvimento da civilização; pode permanecer compatível com a civilização (FREUD, 1997: 50).
\end{abstract}

Podemos dizer que o desenvolvimento da civilização tende a tornar mais asfixiante a vida, na medida em que o sentimento comum nos guia como realidade preponderante diante dos nossos desejos. Para Freud, o amor é o que está em jogo nesse processo. Instância fundante da família, o amor opera na civilização reunindo e conservando considerável

\footnotetext{
${ }^{1}$ Explica Freud: "A vida humana em comum só se torna possível quando se reúne uma maioria mais forte do que qualquer indivíduo isolado e que permanece unida contra todos os indivíduos isolados. O poder dessa comunidade é então estabelecido como 'direito', em oposição ao poder do indivíduo, condenado como 'força bruta'. A substituição do poder do indivíduo pelo poder de uma comunidade constitui o passo decisivo da civilização" (1997: 49).
} 
quantidade de pessoas. Mais que isso, o amor é um recurso para combater o abandono - "se não faço as concessões, serei abandonado". Nesse sentido, o desenvolvimento da civilização tende a privar gradativamente o homem de mais prazeres em nome da preservação de seus moldes. Como sintetiza Freud, "o homem civilizado trocou uma parcela de suas possibilidades de felicidade por uma parcela de segurança" (1997: 72).

Ao verificar o efeito dessa condição no ocidente civilizado, Freud aponta para as bases da crise do indivíduo no Século XX, em suas sensações de desamparo e angústia. Quais os limites dos ímpetos e desejos e até que ponto a privação destes pode tornar trágica a vida? A luta de resistência individual em relação às forças sociais foi problematizada por Simmel, que tomou determinados aspectos da vida, tais como a moda, o dinheiro e o coquetismo, como exemplos de elucidação de suas teorias. As oscilações entre o momento em que nos encontramos como amálgamas do grupo e o momento em que necessitamos de uma distinção individual em relação ao mesmo - esse é o ponto que engendra os dramas da vida moderna.

\section{A Tragédia na Cultura em Simmel}

Ao olhar para a sociedade moderna, Simmel vêuma relação de forças entre os níveis individual e social, que configura um impulso dual de tendências: por um lado, a pessoa anseia por ser singular e tende a romper, se descolar da dimensão social; por outro lado, há a necessidade de se afirmar como igual, como pertencente a um grupo que o acolhe ${ }^{2}$. "Luta entre partes da essência", que se desenham por uma subjetividade em conflito com as forças sociais e constitui o drama do ocidente moderno. Ao longo da modernidade, o processo histórico de gradativo descolamento da percepção subjetiva em relação aos níveis objetivos e fixados coletivamente permite contrastar indivíduo e sociedade sob a luz do conflito. De acordo com Simmel o conflito se dá através da inerência do indivíduo na sociedade.

\section{A divergência mais abrangente e profunda entre indivíduo e sociedade não me parece estar ligada a um só tema de interesse, e sim à forma geral da vida individual. A sociedade quer ser uma totalidade e uma unidade orgânica, de maneira que cada um de seus indivíduos seja}

\footnotetext{
${ }^{2}$ Diz Simmel: "Acima de tudo o significado prático do ser humano é determinado por meio da semelhança e da diferença. Seja como fato ou como tendência, a semelhança com outros não tem menos importância que a diferença com relação aos demais; semelhança e diferença são múltiplas maneiras, os grandes princípios de todo desenvolvimento externo e interno. Desse modo a história da cultura da humanidade deve ser apreendida pura e simplesmente como a história da luta e das tentativas de conciliação entre esses dois princípios" (SIMMEL:2006, 39-58).
} 


\begin{abstract}
apenas um membro dela; a sociedade demanda que o indivíduo pregue todas as forças a serviço da função especial que ele deve exercer como seu integrante; desse modo, ele também se transforma até se tornar o veículo mais apropriado para essa função. Não há dúvida de que o impulso de unidade e totalidade que é característico do indivíduo se rebela contra esse papel. Ele quer ser pleno de si mesmo e não somente ajudar a sociedade a se tornar plena; ele quer desenvolver a totalidade de suas capacidades sem levar em consideração qualquer adiamento exigido pelo interesse da sociedade (SIMMEL, 2006:84).
\end{abstract}

No texto sobre a tragédia da cultura, Simmel destaca dois movimentos sequentes na relação entre o indivíduo e a realidade externa. O primeiro é o fato de que não há ordem préestabelecida na relação entre o homem e o ambiente que o cerca. Há um embate provocado pela capacidade de se colocar à parte desse ambiente, se contrapor e lutar. O segundo momento ocorre quando construções são erigidas dentro do espírito constituindo uma forma de estabilidade e existência, capaz de gerar tensões ${ }^{3}$. Tomando essa lógica sob um aspecto um tanto metafísico, a cultura figura como caminho para a alma se encontrar e se constituir como no sistema nietzschiano, que mais tarde foi trabalhado por Heidegger. O ser se constitui enquanto presença no tempo; a vida passa no decurso do tempo. Nesse sentido, estar no mundo implica na condição humana de se perfazer constantemente. $O$ eterno devir impõe ao homem o caminho do desenvolvimento da totalidade da alma (1998:80). Partindo da ideia de cultura como feixe de linhas de crescimento que vão da unidade fechada, passando pela pluralidade desenvolvida até a unidade desenvolvida (1998:81), temos o paradoxo que põe em rota de colisão o processo de desenvolvimento da alma e a cultura. Quando a pluralidade desenvolvida não acomoda a sensação de desenvolvimento da alma, as possibilidades de se encontrar um $e u$ verdadeiro ficam travadas em nome das forças coletivas (1998: 82).

O sujeito nasce dentro de determinadas instituições, tais como os códigos moral e religioso, o direito e a técnica, e funde-se a estas como se fizessem parte de si. Constitui-se, assim, de forma mais ou menos estável, lutando inclusive pela preservação e manutenção dessas estruturas. Para Simmel (1998), no curso do pensamento nietzschiano, o homem nunca será um ser acabado; ao contrário, é dotado de possibilidades infinitas sobre as quais se projeta. O ponto da crise é, portanto, a tensão gerada pela discrepância entre o ambiente externo e a elaboração interna que o indivíduo faz desse espaço que o cerca; o indivíduo é jogado no mundo sem que sua vontade participasse das suas condições. Se o que vai definir o

\footnotetext{
${ }^{3}$ Ver primeiro parágrafo de $O$ conceito e a Tragédia na Cultura em SOUZA, Jessé e ÖELZE, Berthold. 1998. Simmel e a modernidade.Brasília: UnB. p. 79 -108.
} 
futuro do sujeito são as escolhas que ele faz ou as determinações que o cercam, esse é um debate que se estende por todo o século $\mathrm{XX}^{4}$. Cabe, por ora, situar o tema do mal-estar na relação entre indivíduo e sociedade.

De acordo com Simmel, as forças de criação e desenvolvimento da alma sucumbem diante dos modelos fixos através dos quais os processos de vida se desenvolvem. Descreve como os valores atravessam os processos de subjetivação e se desenvolvem na síntese da cultura; nesse ponto, encontramos desde aqueles que se preocupam apenas com o desenvolvimento pessoal, individual da alma, até aqueles que buscam somente a perfeição objetiva dos moldes instituídos. O ponto é que o valor cultural é referência a todos, seja para sua negação, seja para sua afirmação, o que implica em nivelar as coisas de acordo com as significações fixadas na cultura objetiva ${ }^{5}$. De fato, as manifestações do espírito também têm muito a dizer sobre a cultura, apesar de adquirirem significação apenas enquanto obras do espírito.

Simmel vê com preocupação a força avassaladora do espírito objetivo sobre a subjetividade. Ao orientar-se pelo desenvolvimento da totalidade, o espírito objetivo assume caráter de ideal ético e torna-se um imperativo tão potente que nada podemos fazer em favorecimento da nossa alma; o nosso desenvolvimento se adapta e reforça os valores objetivos, tomando-os como referências para o caminho de nossas vidas (1998:93).

Nas grandes cidades, o primeiro traço notável é o do excesso de estímulos, fator que irá determinar a vida psíquica do indivíduo. A avalanche de estímulos característica das metrópoles cria algum tipo de reserva, uma proteção contra a quantidade de impressões, como uma capa protetora do ambiente externo. Para tanto, exige o predomínio do intelecto sobre as emoções. $\mathrm{O}$ contraste entre o excesso de estímulos e a resistência individual marca o primeiro indício de luta entre indivíduo e sociedade. A elaboração interna que o indivíduo faz de si em relação aos outros e ao conjunto de realizações, saberes e normas objetivas e instituídas na sociedade pode levá-lo à sensação de desamparo, isolamento. Pois nesse ponto está o embate entre a cultura objetiva e a cultura subjetiva.

\footnotetext{
${ }^{4}$ Tendo como matriz a fenomenologia de Husserl, poderíamos mencionar Sartre, Heidegger e Merleau-Ponty como caminhos correntes do existencialismo que ao longo do Século $\mathrm{XX}$ discutiram a questão da intencionalidade, da liberdade individual e da capacidade de operar do ser no mundo. $\mathrm{O}$ rico debate, porém, se descola das pretensões do trabalho, visto que nos atemos aqui a somente expor a condição do homem moderno que conduz ao trágico.

${ }^{5}$ Simmel cita o exemplo da arte: "muitas obras artísticas, técnicas e intelectuais que ficam abaixo da altura já alcançada por outras têm, no entanto, a capacidade de inserir-se da maneira mais efetiva no caminho de várias pessoas como catalisador de suas forças latentes, como ponte para a estação superior seguinte" (Simmel, 1998:92).
} 
Quando problematizou a metrópole e seus efeitos na vida mental, Simmel apontou três constructos fundamentais do homem moderno: o dinheiro, a pontualidade e o predomínio do intelecto sobre as emoções. A vida nas cidades passou a ser orientada pela lógica da exatidão. Sobre a pontualidade, Simmel cita a difusão universal dos relógios de bolso como forma de calcular eficazmente o tempo gasto para as tarefas e relacionamentos (1979:17).

Em paralelo, a economia monetária aponta para as metrópoles; o dinheiro enquanto medida de equivalência a quaisquer mercadorias está concentrado nas metrópoles. Como diz Simmel, "reduz toda qualidade e individualidade à questão: quanto?" (1998: 15). O dinheiro imprime um caráter impessoal, o que viabiliza associações objetivas, atividades de caráter puramente técnico; não obstante, abalou a estrutura subjetiva de personalidade. Um exemplo desse caráter impessoal dado por Simmel está nas sociedades anônimas, que não atuam como pessoas e sim como agregados monetários. A capacidade do dinheiro substituir coisas, até mesmo valores, é crescente, ao passo que essa impessoalidade nas relações tende a distanciar os indivíduos. "Forma-se então, um novo fio condutor para os conteúdos de vida que podem ser associados" (1998:25). O autor evidencia a potência do dinheiro de fazer sucumbir tudo a mero valor de troca, como nos casos em que homens abdicam de princípios e valores ante seu poder. Nas relações conduzidas sob a égide da economia monetária, a interação é livre de subjetividade ou qualquer disposição interna do ser. Por essa razão, “a economia monetária e o domínio do intelecto estão intrinsecamente vinculados" (1979:15).

A precisão, o calculismo e a razão são exigências das metrópoles que, ao intensificar os estímulos, demandam mais do sujeito do que ele é capaz de elaborar. Nas metrópoles, tudo é reduzido à precisão, à exatidão. Desconsidera os limites da dimensão humana e erradica a esfera pessoal ao imprimir o ritmo da pontualidade pautada no tempo comum, da economia enquanto forma de associação autonomizada capaz de ser a medida de todas as coisas e da razão predominante.

Simmel ao olhar para a metrópole via indivíduos com suas vidas submetidas ao cálculo do tempo, do dinheiro e da atenção dispensada. Incansável crítico da modernidade, seus textos são dotados de conteúdo ontológico e ético. O autor buscava alertar para os rumos do contexto que produz solidão, desamparo, melancolia, desumanidade. Como Freud, buscou vias de tradução dos dramas da vida moderna. As crenças na razão se esvaíram em meio à sensação de angústia. Do ímpeto à realização, o caminho da satisfação dos desejos se torna mais distante na medida em que a civilização ocidental se desenvolve. 
Os expressionistas viveram esse turbilhão de acontecimentos. Não mais viam os meios de expressão convencionais, ou seja, baseados na lógica racional, como adequados a seu tempo. Deformavam a realidade para mostrar faces da amargura. Em Estética e sociologia, Simmel explica a necessidade de expressão de formas assimétricas e irracionais, refúgio da arte expressionista.

Enquanto a vida for ainda instintiva, afetiva, irracional, a liberação estética com relação a ela aparece sob uma forma racionalista. Quando ela se vê penetrada pelo entendimento, pelo cálculo, pelo equilíbrio, só então a necessidade estética se refugia no oposto, a busca irracional e a forma exterior irracional, assimétrica (SIMMEL,1998:8).

O racionalismo próprio do mundo moderno encontra escape na arte expressionista, que abandona o compromisso com a simetria em favor das deformações e da organização irracional das figuras. Diametralmente oposto ao traço que caracteriza a metrópole, o quadro expressionista é marcado pelo predomínio da emoção sobre o intelecto.

\section{A versão de Kirchner}

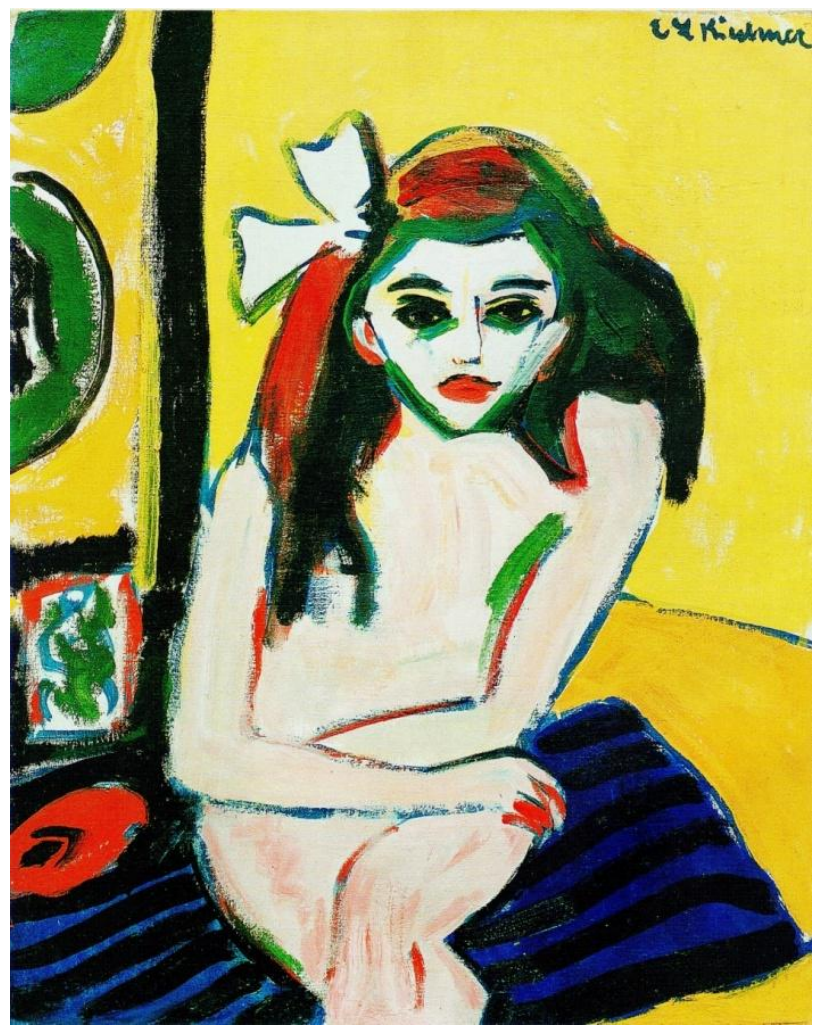


Até a modernidade o conceito de belo orientou o pensamento sobre a arte. Uma das principais definições daquilo que agrada ou produz uma impressão de deleite é a que defende a harmonia das formas e o equilíbrio entre cores, luzes e planos. Por outro lado, Kirchner despreza completamente a harmonia. Seu quadro é uma obra trágica. Antes de expor como o quadro Marcella se opõe ao belo e se apresenta como tragédia, faremos uma breve descrição da obra.

Kirchner chegou a essa pintura a partir do quadro de Edvard Munch, A Puberdade (v.p. 91). Munch combinou a angústia da sexualidade e o complexo erótico-trágico provocado pela culpa. Na tela de Kirchner, a figura se torna amarga e desagradável em relação ao quadro de Munch. De composição e técnica menos erudita, Marcella é a pintura da jovem nua sentada inclinada para frente, com os braços cruzados apoiados sobre as pernas, mas também como se estivesse protegendo a região do quadril. O corpo e o fundo têm poucos detalhes; todo destaque é dado para o rosto da jovem. Os poucos tons de cores se restringem ao vermelho, na boca e nas unhas da jovem, o azul, no assento ou tapete onde está sentada, o amarelo, no fundo, e o verde, nos contornos, sombras e objetos ao fundo. A nota branca é a do laço na cabeça. O rosto é pálido, sombreado, desequilibrado em relação à luminosidade e ao resto do corpo. As sombras do rosto são contornos feitos em traços na cor verde escuro, espessos, quase primitivos. Reforçam a dureza do rosto. Lembrando, a técnica remete ao trabalho de xilogravura; indica que o rosto foi produzido sob a força do talho. A impressão de que o rosto é um recorte causa no observador uma sensação de mal-estar, quase uma angústia, segundo Argan (1996: 253).

\footnotetext{
A figura de Kirchner é uma imagem que o pintor exprime ou extrai penosamente de si, um fragmento vivo de sua própria existência. É, em suma, algo inquietante, quase monstruosamente vivo que o pintor introduz no mundo, comunica: é exclusivamente essa descarga de tensão volitiva que caracteriza a estrutura expressionista, em face da estrutura ainda representativa dos impressionistas, dos fauves e do próprio Cubismo (1996: 256).
}

A composição de formas rígidas, a palidez do rosto e a sombra esverdeada são alterações naquilo que Kirchner vê, no curso do processo criativo. Quando um signo sai de sua cabeça para se materializar no quadro em cores e traços, sai "como fragmento vivo de sua existência", uma vez atravessado por questões existencialistas. O quadro Marcella não escapa 
da tensão provocada pelo conflito entre realidade e prazer que está presente em Freud e, de uma forma mais ampla, em Nietzsche.

A figura humana pintada na tela possui tons não naturais - veja as faixas verdes como sombras e mesmo o róseo que se distribui pelo corpo de forma não homogênea. As cores são chapadas, sem qualquer profundidade ou perspectiva. Se pensarmos nesse quadro à luz de outros retratos femininos, ainda que contemporâneos, como A toalete (1896 - ToulouseLautrec; v.p. 92), Mademoiselle Lanthelme (1907 - Boldini; v.p. 93) ou mesmo Mulher de combinação (1906 - André Derain; v.p. 94), podemos facilmente dizer que Marcella é um quadro "amargo, monstruosamente vivo", como colocou Argan (2003:255), ou desprovido de beleza. No entanto, cabe destacar que o uso da categoria do feio como instrumento de distinção serve apenas para dialogar com o pensamento que entoa o estilo artístico. E nesse caso, Apolo, a representação máxima do belo no plano do pensamento mítico grego, é desprezado por Nietzsche e por Kirchner. Além disso, como salienta Machado (2006a:210), há uma relação próxima entre o apolíneo e a racionalidade, a lucidez. Por outro lado, a arte expressionista é a arte da embriaguez. Como produto das leituras sobre o impulso criador, uma experiência dionisíaca baseada no êxtase e vivenciada espiritualmente como devir das coisas, Kirchner relaciona sua arte com o dionisíaco nietzschiano, explica o crítico de arte Dietmar Elger (1998:18). O ponto é que a correspondência entre a arte e a vida em Kirchner se dá em oposição ao belo; nasce como uma tragédia. E nesse sentido, podemos dizer que sua arte, especialmente o quadro em questão, Marcella, se opõe ao belo. Uma pintura sem sombras, sem luzes, chapada; um rosto recortado, um plano de fundo prensado. Um quadro trágico, por assim dizer.

\section{Conclusão}

Nessa atmosfera anti-idealista, crítica da civilização moderna e pessimista com relação não apenas ao futuro da sociedade alemã recém-unificada, mas de toda cultura européia, Freud (1856-1939) e Simmel (1858-1918) figuram como intelectuais das ciências humanas. Neste trabalho, suas inclinações giram em torno da relação conflituosa entre indivíduo e sociedade. O trágico em Simmel nasce do conflito entre as estruturas formais (a cultura objetiva) e uma energia vital que o indivíduo lança de si e que tende ora a rebentar tais formas, ora a reforçá-las. A tragédia na cultura é notar que o desenvolvimento do espírito e a 
satisfação das vontades se perde em face dos interesses coletivos e das formas autônomas. Em Freud, o processo civilizatório tende a aumentar o fosso entre satisfação dos desejos e a sensação de segurança. Nesse rumo, a vida consiste em se doar para não perder o amor dos outros. O ambiente descrito foi vivenciado pelo jovem pintor Ernst Kirchner (1880-1938). Na representação de seus personagens, há luta. Seja de resistência ou de conformidade, de revolta ou de assimilação. Não importa se Édipo irá matar ou não o pai; não importa o ocasional vencedor de tal luta, sempre há o penoso enfrentamento capaz de fazer, de cada indivíduo, um herói, na tragédia da vida real. Nos quadros de Kirchner, a figura humana é atravessada de emoção ou de indiferença; estados psíquicos estão presentes nas faces, compostas por traços intempestivos e cores vívidas. O movimento dos rabiscos sugere que o próprio processo criativo foi uma tarefa penosa para o criador. Linhas nervosas e impetuosas desenham violentamente formas dionisíacas, desequilibradas, irracionais. O ponto de interseção entre Freud, Simmel e Kirchner envolve o drama da sociedade moderna e civilizada, na $1 v^{\text {tr }}$ ontra os mecanismos repressores.

\section{Referências bibliográficas:}

ARGAN, Giulio Carlo. Arte Moderna. São Paulo: Cia das Letras,1997.

ELGER, Dietmar. Expressionismo: uma revolução alemã na arte. Tradução: Ruth Correia. Lisboa: Tachen, 1998.

FEHLEMANN, Sabine (org.). Expressionismo alemão - destaques da coleção Von der Heydt-Museum. São Paulo: Editora MAM-SP, 2000.

FREUD, Sigmund. O Mal-Estar na civilização. Rio de Janeiro: Imago, 1997. . A Interpretação dos Sonhos. Rio de Janeiro: Imago,1996. Além do Princípio do Prazer. Rio de Janeiro: Imago,1996 a.

MACHADO, Roberto. O Nascimento do trágico - De Schiller a Nietzsche. Rio de Janeiro: Jorge Zahar, 2006.

MOELLER, Magdallena. "Die Brücke a Dresda e Berlino". In. Espressionismo: prezenza della pintura in Germania 1900-2000.Catálogo da Exposição na Fondazione Pallazo Bricherasio di Torino (2001-2002).

NIETZSCHE, Friedrich. Aurora: reflexões sobre os preconceitos morais. Rio de Janeiro: Vozes, 2000 a. 
. O Nascimento da tragédia no espírito da música. São Paulo: Cia das Letras, 2006. . Coleção Os Pensadores. São Paulo: Abril Cultural, 1978.

READ, Herbert. A arte de agora. São Paulo: Perspectiva, 1981.

SIMMEL, Georg. A metrópole e a vida mental. In. VELHO, Otávio Guilherme (org.). O Fenômeno urbano. Rio de Janeiro: Zahar Editores, 1979.

Sociologia: Coleção Grandes Cientistas Sociais. Org. Evaristo de Moraes Filho. São Paulo: Ática, 1983.

O Dinheiro na Cultura Moderna in Simmel e a Modernidade. Orgs. Jessé Souza e Berthold Öelze. Editora UNB, 1998, p. 23-40.

O Conceito e a Tragédia da Cultura In, Jessé Souza e B. Oëlze, orgs. Simmel e a Modernidade. Brasília, Editora da UNB, 1998, p.79-108.

O indivíduo e a liberdade. In, Jessé Souza e B. Oëlze, orgs. Simmel e a Modernidade. Brasília, Editora da UNB, 1998, p. 109-117.

WOLF, Norbert. Kirchner. Lisboa: Taschen, 2004. 